Response latencies in delayed

\section{matching-to-sample as a function of delay interval and social condition}

\author{
VAUGHN E. STIMBERT \\ University of Tennessee Child Development Center, Memphis, Tenn. 38105
}

Human Ss were presented delayed matching problems and were free to control the duration of looking at both sample and comparison stimuli. Response latencies were recorded as a function of delay interval and social condition. Latencies to sample stimuli were consistently longer than to comparison stimuli and were an increasing monotonic function of delay interval Errors were inversely related to the duration of the delay interval. The opportunity to observe another $\mathrm{S}$ complete the matching program decreased both sample and match response latencies.

Matching to sample has been defined as "a simultaneous conditional discrimination in which only one of two or more stimuli corresponds to or matches a sample stimulus, and in which only responses to the stimulus that matches the sample stimulus can be reinforced [Catania, 1968]." Matching has a long history as a technique in experimental psychology and as a teaching method. It has been found useful in investigating discrimination (Moore \& Goldiamond, 1964), generalization (Nissen, Blum, \& Blum, 1948; Cohen, 1969; Sidman, 1969), programmed learning (Ferster \& Hammer, 1966; Hively, 1962, 1964 Holland, 1962), and attention processes (Siegelman, 1969).

Although most studies have utilized simultaneous matching in which the comparison stimuli are present at the same time as the sample stimulus, the imposition of a delay between the presentation of sample and comparison stimuli has the advantage of allowing the study of variables affecting retention and provides an opportunity for isolating those behaviors that might be prerequisite for successful matching. Of critical importance would seem to be a knowledge of the distribution of attention to both sample and comparison stimuli. In this regard, Premack \& Collier (1966) have shown duration of looking to be a sensitive dependent measure in the study of simple discrimination learning.

The present experiment was designed to study the relationship between the amount of time spent viewing the sample (standard) stimulus and the amount spent viewing the comparison (matching) stimuli and to determine how these are affected by length of delay interval and social variables.

\section{SUBJECTS}

The Ss were 110 undergraduate students enrolled in introductory psychology. Although participation was voluntary, they were given extra course credit.

\section{APPARATUS}

The apparatus was a Lehigh Valley Human Console placed on a table in a room approximately $6 \mathrm{x} 8 \mathrm{ft}$. Four translucent panels (each $3 \times 5$ in.) were arranged on the front of the console with a single panel centered above the other three positioned horizontally. Sample stimuli were presented on the upper panel, and comparison stimuli were presented on the lower panels. Microswitches located behind each panel allowed the recording of response latencies and errors. Two counters and two red lights were located in the upper left corner of the console. One counter was labeled "correct" and the other "errors."

Sample and comparison stimuli were projected from $35-\mathrm{mm}$ slides by a Carousel projector located $3 \mathrm{ft}$ behind the console. The projector was modified to read slides coded by $1 / 32$-in. holes in one of four positions on the slide. The upper position was used for the sample slides and the three below for Comparisons 1-3 (left to right), respectively. Programming equipment was located in an adjoining room, and the $S$ could be observed through a one-way window. Timing intervals were set by a recycling interval timer, and responses were recorded on a 20-pen Esterline-Angus event recorder.

\section{PROCEDURE}

The experimental design was a 3 by 5 factorial with five delay intervals and three social conditions. Due to unequal cell frequencies, the experiment was analyzed in terms of a single-factor experiment with unequal sample sizes (Winer, 1962). Tests on differences between all pairs of means were conducted with the Newman-Keuls method (Winer, 1962).

The Ss were assigned at random to one cell of the design. The delay interval and social condition remained constant for each $\mathrm{S}$. Slide sequence and position of correct match were also the same for each S. Delay intervals imposed between sample and match were $2,10,20,30 \mathrm{sec}$, or a variable delay (VD) with three 10 -sec and three 20-sec delays interspersed within 34 delays of $2 \mathrm{sec}$ each. The three social conditions were: (1) isolate (S performs alone), (2) social (S performs with another $S$ present), and (3) observer (observer of social $S$ then performs as isolate). The observer Ss were positioned with a clear view of the console. Their delay intervals were the same as those of the social Ss whom they observed.

The stimulus materials consisted of 40 pairs of slides taken from the Hereward Matching Series-Grade 2 (Philograph Publications Ltd.). No two samples were identical; however, some designs were found on more than one pair of comparison slides. A typical comparison design is shown in Fig. 1.

The sequence began with a sample design projected on the upper panel. Pressing this panel removed the sample and imposed the predetermined delay interval terminated by advancement of the projector to the second slide containing the three comparison designs, one of which was identical to the sample. By pressing the matching panel, the next sample was presented after a 1-sec transport delay. Also, the counter labeled "correct" advanced one digit, and its associated light came on briefly. If one of the two nonmatching panels was pressed, the projector stepped back one slide and repeated the sample. Thus, by continuing to make errors, the $S$ would alternate from sample to comparison on the same pair of slides and would not advance in the program. Each nonmatching response produced a count and light on the counter labeled "errors."

The following instructions were given to all Ss: "This is a matching task. A design will be presented on the upper window. Look at it until you think you can remember it and then press it. The design will disappear and after some time, three designs will appear on the lower panels. Press the one which you think matches the one above. When you are correct, this light will come on and you will get a point followed by another design on the upper window. When you are incorrect, this light will come on, you will have an error recorded, and the prohlem will be repeated."

The Ss serving as Os were given the following additional instructions: "You are to watch the person on the console because when he (she) is finished it will be your turn. Please do 

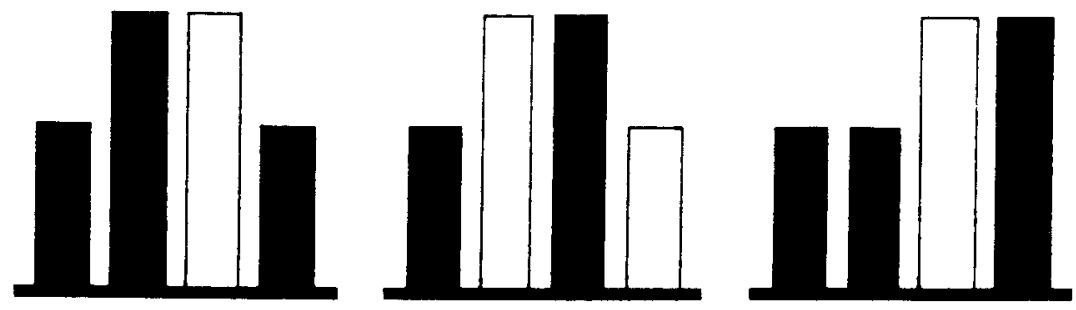

Fig. 1. Example of comparison design.

not talk to each other during the experiment."

\section{RESULTS}

Response latencies to sample and comparison stimuli and errors are shown in Fig. 2 as a function of delay interval for the three social conditions. The data are consistent in showing longer latencies for sample than for comparison responses $(\mathrm{F}=66.97 \mathrm{df}=$ $1 / 208, p<.01$ ). Out of $110 \mathrm{Ss}$ in the experiment, 104 showed this relationship in their performance.

Sample response latencies increased significantly as a function of delay interval $(\mathrm{F}=3.62, \mathrm{df}=4 / 105$, $\mathrm{p}<.01)$. A comparison of means showed significant differences between the following delay intervals: 20-2, $30-10 \quad(\mathrm{p}<.05) ; \quad 30-2,30-\mathrm{VD}$ $(\mathrm{p}<.01)$.

Comparison response latencies also increased as a function of delay interval $(F=2.76, \mathrm{df}=4 / 105$, $\mathrm{p}<.05$ ), with differences between $30-2,20-V D$ significant at the .05 level and differences between $30-V D$ significant at the .01 level. Errors decreased significantly as a function of delay interval $(F=5.19$, df $=4 / 105$, $\mathrm{p}<.01$ ). Significant comparisons were between VD-10, 20, $30(\mathrm{p}<.01)$ and $2-20, \quad 30 \quad(p<.05)$. Within-session performance was examined and found to be stable, with the exception of a decrement on the initial stimuli.

Social condition was also found to have an effect on looking times with decreased response latencies associated with those Ss assigned to the observer condition. They differed from both the isolated $(\mathrm{F}=9.56, \mathrm{df}=2 / 107$, $\mathrm{p}<.01)$ and the social $(\mathrm{F}=4.50, \mathrm{df}=$ $2 / 107, p<.05)$ Ss on sample latencies, but only from the isolated $(\mathrm{F}=8.88$, $\mathrm{df}=2 / 107, \mathrm{p}<.01)$ Ss on comparison latencies. Number of errors were not significantly different across social groups.

\section{DISCUSSION}

It should be noted that the procedures in this experiment differ in some respects from previous studies using duration of looking as a dependent variable. Premack \& Collier (1966), Siegelman (1969), and D'Amato, Etkin, \& Fazzaro (1968) have made access to discriminanda contingent on an observing or cue-producing response. In one procedure, each response produces a brief exposure to the discriminanda (e.g., .2 sec), and in another, the $S$ must maintain contact with a key or panel to present stimuli while a release removes the stimulus. In contrast, the present study used a procedure in which responses always terminated the stimuli. Thus, continuous, possibly distracting motor behavior was not required.

These results demonstrate highly reliable differences between response latencies to sample and comparison stimuli and show that these times are longer for sample than for comparison under a wide range of delay intervals and social conditions. Such a distribution of attention appears to be an efficient strategy for this particular task in that an earlier unpublished study demonstrated the reverse relationship with children and found poorer performance associated with this tactic. The enforcement of longer sample times in Ss who typically remove the standard before some optimal period would be of interest if changing the distribution of attention resulted in improved performance. Hopefully, further studies will clarify the limitations of establishing more effective observing behavior in a wide variety of Ss and also point out the developmental aspects of matching behaviors.

Using a matching paradigm but entirely different stimuli and procedures, both Siegelman (1969) and Kagan (1965) report a mean duration per look of 3 sec. This value is also typical of this study and the previously mentioned study using children.

The increasing time devoted to the sample (and to a lesser extent the comparison stimuli) with increasing delays suggests that long delays are perceived by the $\mathrm{S}$ as more difficult. The overall effect, however, is to reduce errors. Whether this is, as has been suggested earlier, due to increased looking time initially, to added "rehearsal" time during the delay interval, or to some combination is not known. This finding is similar to

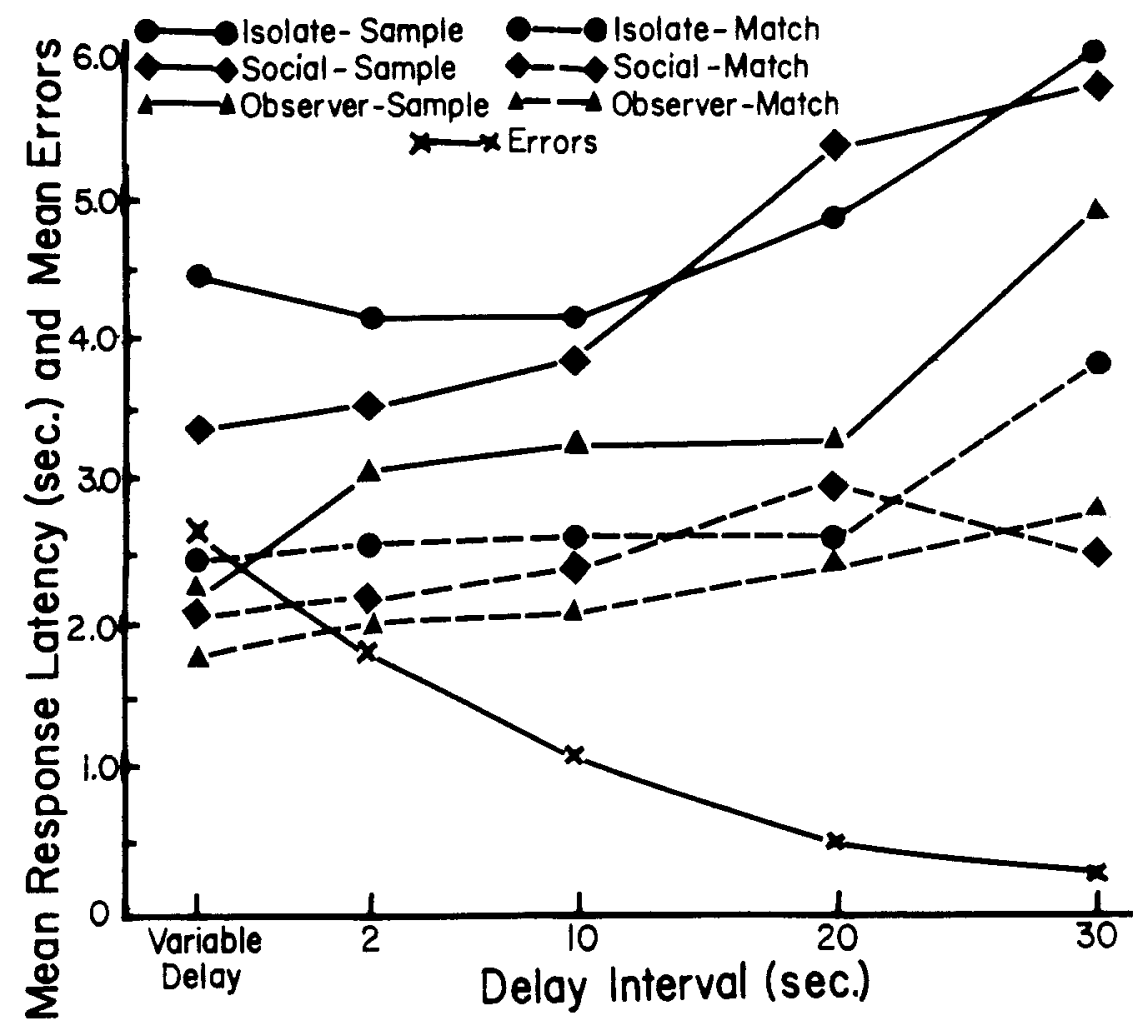

Fig. 2. Mean latency and errors as a function of delay interval. 
studies showing a delay-retention effect (Sturges, Sarafino, \& Donaldson, 1968) in information feedback.

Observational learning was demonstrated to occur in this study and had the general effect of lowering both sample and comparison looking times. It would be interesting to compare the observer group with another group having extra practice instead of observation to determine the efficiency of observational learning. It is clear that improved performance can occur as a result of a passive period of observation, a finding which is consistent with much recent work on observational or imitative learning.

\section{REFERENCES}

CATANIA, A. C. (Ed.) Contemporary research in operant behavior. Glenview, IU: Scott, Foresman, 1968 .

COHEN, L. R. Generalization during acquisition, extinction, and transfer of matching with an adjustable comparison. Journal of the Experimental Analysis of Behavior, $1969,12,463-474$

D'AMATO, M. R., ETKIN, M., \& FAZZARO, J. Cue-producing behavior in the Capuchin monkey during reversal, extinction, acquisition, and overtraining. Journal of the Experimental Analysis of Behavior, 1968, 11, 425-433.

FERSTER, C. B., \& HAMMER, C. E., JR Synthesizing the components of arithmetic behavior. In W. K. Honig (Ed.), Operant behavior: Areas of research and application. New York: Appleton-Century-Crofts, 1966.

HIVELY, W. Programming stimuli in matching to sample. Journal of the Experimental Analysis of Behavior, 1962 , 5, 279-298.

HIVELY, W. Parametric experiments with a matching to sample program. In J. G. Holland and B. F. Skinner (Eds.), An analysis of the behavioral processes involved in self-instruction with teaching machines. Harvard University Teaching Machine Project, Final Report, 1964.

HOLLAND, J. G. New directions in teaching-machine research. In J. E Coulson (Ed.), Programmed learning and computer-based instruction. New York: Wiley, 1962.

KAGAN, J, Reflection-impulsivity and reading ability in primary grade children. Child Development, $1965,36,609-628$ MOORE, R., \& GOLDIAMOND. I. Errorless establishment of visual discrimination using fading procedures. Journal of the Experimental Analysis of Behavior, 1964 , 7, 269-272.

NISSEN, H. W., BLUM, J. S., \& BLUM, R. $H$. Analysis of matching behavior in chimpanzees. Journal of Comparative \& Physiological Psychology, 1948, 41 , 62-74.

PREMACK, D., \& COLLIER, G. Duration of looking and number of brief looks as dependent variables. Psychonomic Science, $1966,4,81-82$.

SIDMAN, M. Generalization gradients and stimulus control in delayed matching-to-sample. Journal of the Experimental Analysis of Behavior, 1969 12, 745-757.

SIEGELMAN, E. Reflective and impulsive observing behavior. Child Development 1969, 40, 1213-1222.

STURGES, P. 'T., SARAFINO, E. P., \& DONALDSON, P. L. Delay-retention effect and informative feedback. Journal of Experimental Psychology, 1968, 78, 357-358.

WINER, B. J. Statistical principles in experimental design. New York: MeGraw-Hill, 1962. 